\title{
Development of an evidence-based clinical imaging diagnostic guideline for implant planning: Joint recommendations of the Korean Academy of Oral and Maxillofacial Radiology and National Evidence-based Healthcare Collaborating Agency
}

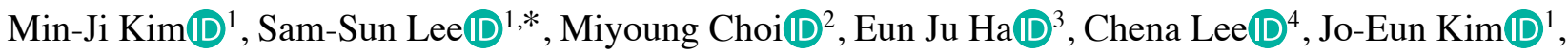 \\ Min-Suk Heo(D) ${ }^{1}$ \\ ${ }^{1}$ Department of Oral and Maxillofacial Radiology and Dental Research Institute, School of Dentistry, Seoul National University, Seoul, Korea \\ ${ }^{2}$ Division for Healthcare Technology Assessment Research, National Evidence-based Healthcare Collaborating Agency, Seoul, Korea \\ ${ }^{3}$ Department of Radiology, Ajou University School of Medicine, Suwon, Korea \\ ${ }^{4}$ Department of Oral and Maxillofacial Radiology, Yonsei University College of Dentistry, Seoul, Korea
}

\section{ABSTRACT}

\begin{abstract}
Purpose: This study was conducted to develop an evidence-based clinical imaging diagnostic guideline for implant planning, taking into account efficacy, benefits, and risks.

Materials and Methods: The guideline development process employed the adaptation methodology used for Korean clinical imaging guidelines (K-CIG). Core databases (Ovid-Medline, Ovid-Embase, National Guideline Clearinghouse, Guideline International Network) and domestic databases (KoreaMed, KMbase, and KoMGI) were searched for guidelines. The retrieved articles were analyzed by 2 reviewers, and articles were selected using well-established inclusion criteria.

Results: The search identified 294 articles, of which 3 were selected as relevant guidelines. Based on those 3 guidelines, 3 recommendations for implant planning were derived.

Conclusion: We recommend radiography or cone-beam computed tomography (CBCT) scanning for individual patients judged to require a cross-sectional image after reading of a panoramic X-ray image and a conventional intraoral radiological image. Various steps should be taken to raise awareness of these recommendations among clinicians and the public, and K-CIG should be regularly reviewed and revised.(Imaging Sci Dent 2020; 50: 45-52)
\end{abstract}

KEY WORDS: Implant; Imaging; Radiography; Cone-Beam Computed Tomography

\section{Introduction}

Diagnostic imaging is an essential component of treatment planning in oral rehabilitation through implant placement. ${ }^{1}$ Clinicians can use conventional radiography or cone-beam computed tomography (CBCT) for diagnostic imaging. CBCT enables clinicians to obtain 3-dimension-

This work received financial support from the Research Program funded by the Korea Centers for Disease Control and Prevention (fund code: 2017E3600100). This study was a co-investigation of the National Evidence-based Collaborating Agency and the Korean Society of Radiology (research number: NECA-S-17-005).

Received September 19, 2019; Revised November 20, 2019; Accepted December 3, 2019 *Correspondence to : Prof. Sam-Sun Lee

Department of Oral and Maxillofacial Radiology, School of Dentistry, Seoul National University, 101 Daehak-ro, Jongno-gu, Seoul 03080, Korea

Tel) 82-2-2072-3978,E-mail) raylee@snu.ac.kr al images. ${ }^{2}$ However, since the radiation doses of dental CBCT are usually higher than those of conventional (2-dimensional) radiography, it is very important to consider the risks of radiation exposure when using CBCT for diagnostic purposes in dentistry. ${ }^{3}$

Clinical guidelines are systematically developed statements that assist clinicians and patients in making decisions about the most appropriate care for specific clinical circumstances. In other words, guidelines can be helpful in situations that require clinicians to choose an appropriate imaging modality. Guidelines are often referred to as "selection criteria" or "referral criteria."

In the field of radiology, developed countries utilize evidence-based clinical imaging guidelines (CIG) to augment

Copyright (c) 2020 by Korean Academy of Oral and Maxillofacial Radiology

This is an Open Access article distributed under the terms of the Creative Commons Attribution Non-Commercial License (http://creativecommons.org/licenses/by-nc/3.0) which permits unrestricted non-commercial use, distribution, and reproduction in any medium, provided the original work is properly cited.

Imaging Science in Dentistry · pISSN 2233-7822 eISSN 2233-7830 
the clinical decision-making of physicians when requesting or prescribing a radiological examination. In Korea, the methodology of developing guidelines is to adapt CIG by modifying previously developed guidelines to make them suitable for the local healthcare environment. ${ }^{4}$ Through this process, this study aimed to develop an evidence-based Korean clinical imaging guidelines (K-CIG) for implant planning, taking into account efficacy, benefits, and risks .

\section{Materials and Methods}

\section{Development of Korean CIG for implant planning}

The guideline development process involved a collaboration between the Korean Academy of Oral and Maxillofacial Radiology (KAOMFR) and the Korean Society of Radiology, and the National Evidence-based Healthcare Collaborating Agency (NECA) organized a development committee and working group to develop this guideline.

Three experts in oral and maxillofacial radiology experts comprised the working group. The working group, research methodology specialists, and clinical guideline specialists who supported the overall planning and research methodology comprised the development committee. ${ }^{4}$ They published a description of the methodology of the guideline adaptation process that was applied in this study. A consensus group consisted of 5 nominated members from the final 5 related academic societies who participated in the symposium conducted to establish a consensus.

\section{Defining the key question}

Questions were generated in the form of population/ patient, intervention/index test, comparator/control, and outcome (PICO) questions by the working group and were reviewed by the development committee and the consensus group. The following key question was identified: for a patient scheduled for implantation, what is the appropriate imaging modality?

\section{Guideline search}

Core databases such as Ovid-Medline, Ovid-Embase, National Guideline Clearinghouse, and Guideline International Network were searched for guidelines. Additionally, 3 domestic research databases (KoreaMed, KMbase, and KoMGI) were searched from 2000 to the first week of March 2017. The pre-search yielded 51 article abstracts. The extensive searches of databases used the terms "dental implant," "radiograph," "guideline," "recommendation," and "practice guideline." The working group reviewed the search strategy and results and performed additional searches to ensure the inclusion of any important omitted guidelines.

\section{Selection of the searched guidelines}

According to pre-defined selection criteria, 2 members of the working group independently reviewed the literature during the primary screening process and secondary selection process to ensure objectivity. The primary screening process involved reviewing the title and abstract of the identified studies and guidelines. In the secondary selection process, the full text of the identified studies was reviewed, and the reasons for excluding studies were noted.

The inclusion criteria for guidelines were as follows: 1) the study population included patients scheduled for implantation, 2) the study intervention was CBCT, 3) the study comparators were panoramic and periapical radiographs, 4) the study assessed the effectiveness of CBCT for evaluating alveolar bone morphology in edentulous regions and its surrounding structures, 5) the study presented a practice guideline, 6) the study presented recommendations, 7) the study utilized an evidence-based method, and 8) the study was published in Korean or English.

The exclusion criteria were as follows: 1) patients of interest for the key question were not included, 2) a key question-related imaging examination was not included, 3) appropriate results (diagnostic accuracy, efficacy, safety, prognosis, and patients' preferences) were not reported, 4) the study presented non-clinical practical guidelines, 5) recommendations were not suggested, 6) the guidelines were not produced via an evidence-based method, 7) the guidelines were reported in neither English nor Korean, 8) the study was an overlapping publication, and 9) the full text was not obtainable.

Disagreements between reviewers were resolved either by consultation between the reviewers or by obtaining input from a third reviewer.

\section{Search for recent literature}

Randomized controlled trials (RCTs) and observational studies were searched, and the recent literature (since 2011) was reviewed.

\section{Quality assessment}

The finally selected guidelines underwent quality appraisal using the Korean Appraisal of Guidelines for Research and Evaluation II (AGREE II) tool. ${ }^{5}$ Two appraisers from the development committee independently assessed 
Table 1. Search results from domestic literature databases

\begin{tabular}{|c|c|c|c|}
\hline \multicolumn{4}{|c|}{ Searching date: March 8, 2017} \\
\hline Search site & Search term & Searched studies & Note \\
\hline \multirow{2}{*}{ KoreaMed } & "Dental Implant" [ALL] AND radiograph* & 0 & \multirow{2}{*}{$\begin{array}{l}\text { Year limitation: } \\
\text { since } 2000\end{array}$} \\
\hline & Sum & & \\
\hline \multirow{7}{*}{ KMbase } & $\begin{array}{l}([\mathrm{ALL}=\text { implant installation }] \text { AND }[\mathrm{ALL}=\text { radiographic examination }] \text { AND } \\
[\mathrm{ALL}=\text { guideline }])\end{array}$ & 0 & \multirow{7}{*}{$\begin{array}{l}\text { Year limitation: } \\
\text { since } 2000\end{array}$} \\
\hline & $([\mathrm{ALL}=$ implant installation $]$ AND $[\mathrm{ALL}=$ bleeding $]$ AND $[\mathrm{ALL}=$ recommend $])$ & 0 & \\
\hline & $([\mathrm{ALL}=$ implant installation $] \mathrm{AND}[\mathrm{ALL}=$ bleeding $] \mathrm{AND}[\mathrm{ALL}=$ guideline $])$ & 0 & \\
\hline & $(([\mathrm{ALL}=$ Dental Implant $]$ AND $[\mathrm{ALL}=$ radiograph $])$ AND $[\mathrm{ALL}=$ recommendation $])$ & 0 & \\
\hline & $(([\mathrm{ALL}=$ Dental Implant $]$ AND $[\mathrm{ALL}=$ radiograph $])$ AND $[\mathrm{ALL}=$ guideline $])$ & 0 & \\
\hline & Sum & 0 & \\
\hline & After omitting overlapping studies & 0 & \\
\hline
\end{tabular}

the selected literature. Each evaluation category was scored on a scale ranging from 1 to 7 points, and the reasoning behind the scores was noted to ensure clarity and reproducibility of the assessment results. If there was a difference $>4$ in scores for any of the categories among the appraisers, the study was re-examined. In essence, guidelines that scored 50 or above in the "rigor of development" domain were considered candidates for inclusion in the development process of Korean CIG (K-CIG). ${ }^{4}$

\section{Grading the level of evidence and drafting the recommendation document}

This step assessed whether an identified guideline was up-to-date, acceptable, and applicable. The level of evidence of the K-CIG was merged with the evidence level of individual studies, and was categorized as high (I), moderate (II), low (III), or very low (IV).

A draft of the recommendation document consisted of recommendations for the key question, summary, and evidence; considerations for the recommendation and references; and each recommendation with its overall evidence level. The recommendations in the K-CIG were graded as A, B, C, or I, indicating the strength of the recommendation.

\section{External review and approval of the clinical guideline}

The finalized recommendation document was reviewed both internally by clinical imaging experts who did not participate in the development of the guideline and externally by related society members (end-users of the guideline). Appropriate modifications were made after collecting opinions.

\section{Results \\ PICO}

The guideline was developed based on the key question, which was generated from the PICO questions by the working group. In this study, the population comprised patients scheduled for implantation. The intervention was CBCT. The comparators were panoramic and periapical radiographs. The outcome was the effectiveness of CBCT for evaluating alveolar bone morphology in edentulous patients and its surrounding structures.

\section{Search for guidelines}

The search results from domestic databases are shown in Table 1. No results were obtained from KoMGI. The search results from international databases are shown in Tables 2 and 3. By searching for "dental implant," 5 search results were obtained from the Guideline International Network and National Guideline Clearinghouse databases.

\section{Selection of searched guidelines}

A total of 294 guidelines were retrieved from the databases. After the exclusion of duplicates, 51 guidelines remained. Finally, 3 guidelines were selected in accordance with the inclusion and exclusion criteria (Fig. 1).

\section{Search for recent studies}

The recent literature (since 2011) was reviewed. This starting point was 3 years earlier than the most recent guideline. RCTs and observational studies that were identified by applying condition number 4 in Table 4 were read; as a result, 6 studies were selected. 
Table 2. Search results from international databases: Ovid-Medline (1946 to first week of June 2017)

Searching date: Jun 8, 2017

Search term

Search result

\begin{tabular}{|c|c|c|}
\hline \multirow{3}{*}{$\begin{array}{c}\mathrm{P} \\
\text { (population) }\end{array}$} & dental implant\$.mp. or Immediate Dental Implant Loading/ or Dental Prosthesis, Implant-Supported/ & 34,406 \\
\hline & Dental Implantation, Endosseous/ or Dental Implants/ or Dental Implant*.mp. or Dental Implantation/ & 31,021 \\
\hline & 1 or 2 & 34,406 \\
\hline \multirow{4}{*}{$\begin{array}{l}\text { I } \\
\text { (intervention) }\end{array}$} & Cone-Beam Computed Tomography.mp. or Cone-Beam Computed Tomography/ & 7,418 \\
\hline & $\begin{array}{l}\text { Radiography, Dental, Digital/ or Radiography/ or Radiography, Dental/ or Radiography, Panoramic/ } \\
\text { or Radiography.mp. }\end{array}$ & 403,580 \\
\hline & periapical radiograph.mp. & 136 \\
\hline & 4 or 5 or 6 & 409,676 \\
\hline \multirow{6}{*}{$\begin{array}{l}\mathrm{P} \& \mathrm{I} \\
\text { guideline }\end{array}$} & 3 AND 7 & 63,024 \\
\hline & guideline $\$ . t i$. & 56,686 \\
\hline & practice guideline.pt. & 23,238 \\
\hline & recommendation\$.ti. & 28,043 \\
\hline & guideline.pt. & 16,544 \\
\hline & 9 or 10 or 11 or 12 & 106,370 \\
\hline $\begin{array}{l}\text { P \& I \& } \\
\text { guideline }\end{array}$ & PAND I AND 13 & 16 \\
\hline P \& guideline & PAND 13 & 135 \\
\hline \multirow[t]{2}{*}{ Limitation } & P \& I \& guideline $2006 \sim$ current & 12 \\
\hline & P \& guideline $2006 \sim$ current & 86 \\
\hline
\end{tabular}

Table 3. Search results from international databases: Ovid-Embase (1974 to week 23 of 2017)

Searching date: Jun 8, 2017

\begin{tabular}{|c|c|c|}
\hline $\begin{array}{l}\mathrm{P} \\
\text { (population) }\end{array}$ & $\begin{array}{l}\text { edentulousness/ or tooth prosthesis/ or denture/ or dentistry/ or tooth implant/ or tooth implantation/ } \\
\text { or dental implant*.mp. or dental surgery/ }\end{array}$ & 155,281 \\
\hline \multirow[t]{4}{*}{$\begin{array}{c}\text { I } \\
\text { (intervention) }\end{array}$} & $\begin{array}{l}\text { Cone-Beam Computed Tomography.mp. or computer assisted tomography/ or cone-beam computed } \\
\text { tomography/ or single photon emission computer tomography/ }\end{array}$ & 683,365 \\
\hline & tooth radiography/ or Radiography.mp. or radiography/ & 548,309 \\
\hline & periapical radiograph.mp. & 155 \\
\hline & 2 or 3 or 4 & $1,099,180$ \\
\hline \multirow{4}{*}{$\begin{array}{l}\mathrm{P} \& \mathrm{I} \\
\text { guideline }\end{array}$} & 1 AND 5 & 10,569 \\
\hline & guideline\$.ti. & 56,686 \\
\hline & recommendation\$.ti. & 28,043 \\
\hline & 7 or 8 & 118,152 \\
\hline $\begin{array}{l}\text { P \& I \& } \\
\text { guideline }\end{array}$ & P AND I AND 9 & 33 \\
\hline$P$ \& guideline & P AND 9 & 657 \\
\hline \multirow[t]{2}{*}{ Limitation } & P \& I \& guideline 2006 current & 21 \\
\hline & P \& guideline $2006 \sim$ current & 272 \\
\hline
\end{tabular}




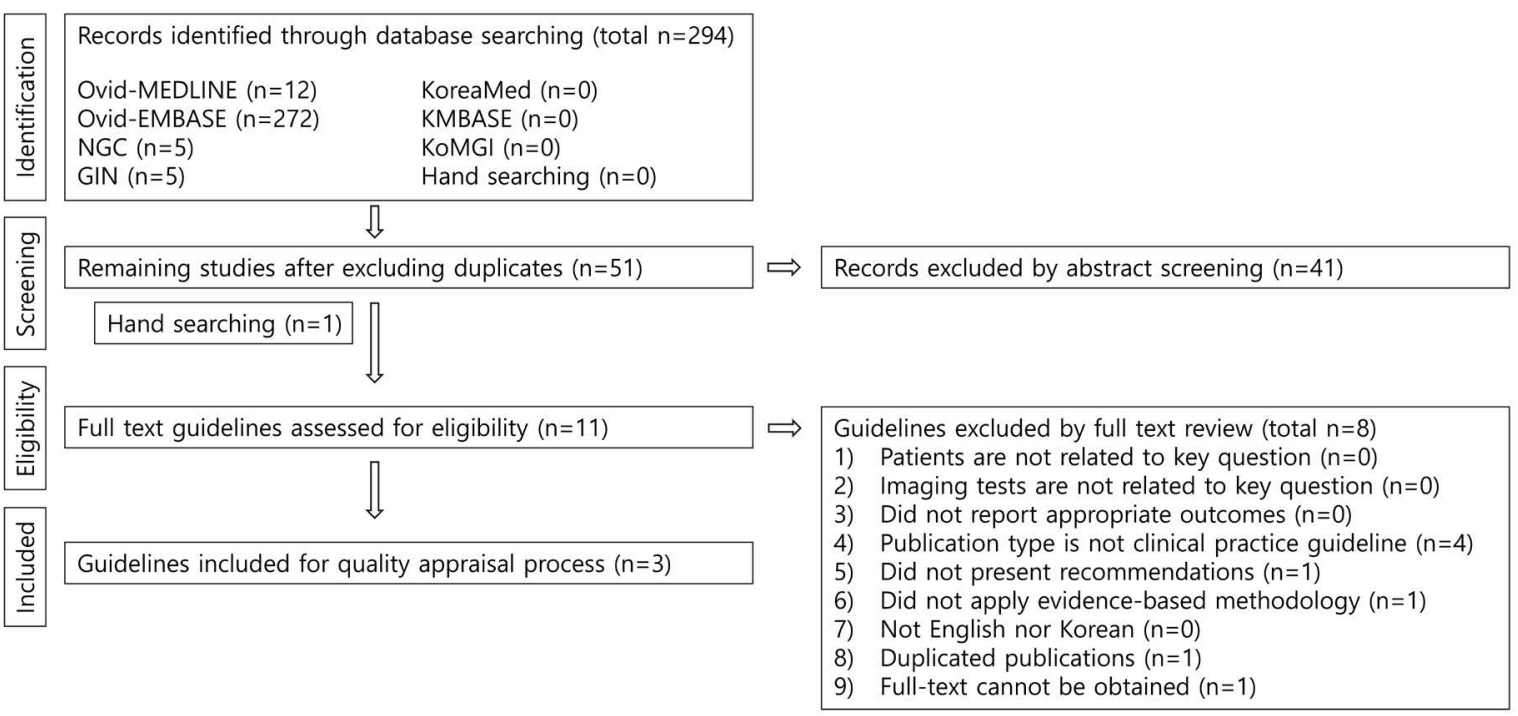

Fig. 1. The guidelines identified by searching were selected by step-by-step screening. This is the flow diagram of guideline selection.

Table 4. Search results of recent literature through Ovid-Medline In-Process and Other Non-Indexed Citations and Ovid-Medline from 1946 to present

Searching date: Oct 12, 2017

\begin{tabular}{|c|c|c|}
\hline \multirow{3}{*}{$\begin{array}{l}\mathrm{P} \\
\text { (population) }\end{array}$} & dental implant\$.tw. or Immediate Dental Implant Loading/ or Dental Prosthesis, Implant-Supported/ & 17,818 \\
\hline & Dental Implantation, Endosseous/ or Dental Implants/ or Dental Implantation/ & 28,672 \\
\hline & 1 or 2 & 33,862 \\
\hline \multirow{4}{*}{$\begin{array}{c}\text { I } \\
\text { (intervention) }\end{array}$} & Cone-Beam Computed Tomography.tw. or Cone-Beam Computed Tomography/ & 9,540 \\
\hline & $\begin{array}{l}\text { Radiography, Dental, Digital/ or Radiography/ or Radiography, Dental/ or Radiography, Panoramic/ or } \\
\text { Radiography.tw. }\end{array}$ & 375,388 \\
\hline & periapical radiograph\$.tw. & 1,542 \\
\hline & 4 or 5 or 6 & 384,195 \\
\hline P \& I & 3 AND 7 & 3,742 \\
\hline $\begin{array}{c}\text { Year } \\
\text { limitation }\end{array}$ & limit 8 to $\mathrm{yr}=$ "2011-Current" & 1,727 \\
\hline RCTfilter & $\begin{array}{l}\text { exp Randomized Controlled Trials/ or Random*.mp. or RCT.mp. or exp Controlled Clinical Trial/ or } \\
\text { exp Placebo Effect/ or exp Placebos/ or Placebo.mp. or trial.mp. }\end{array}$ & $1,759,548$ \\
\hline \multirow{6}{*}{$\begin{array}{l}\text { Observational } \\
\text { study filter }\end{array}$} & exp Epidemiologic Studies/ or exp Case-Control Studies/ or exp Cohort Studies/ or exp & $2,563,395$ \\
\hline & $\begin{array}{l}\text { Seroepidemiologic Studies/ or Case control.mp. or cohort stud*.mp. or cohort analys*.mp. or Follow } \\
\text { up stud*.mp. or observational stud*.mp. or Longitudinal.mp. or Retrospective.mp. }\end{array}$ & \\
\hline & 9 and $10-\mathrm{RCT}$ & 310 \\
\hline & 9 and 11-Observational study & 733 \\
\hline & After omitting overlapping studies (\#12) & 296 \\
\hline & After omitting overlapping studies (\#13) & 697 \\
\hline
\end{tabular}

RCT: randomized controlled trial

\section{Quality assessment}

Table 5 presents the results of the quality assessment of the 3 guidelines using the AGREE II instrument. ${ }^{5}$ All 3 guidelines received scores $>50$ in the "rigor of development" domain, and the committee recommended consulting them. The titles of the 3 guidelines are presented below. 
Table 5. Results of the quality assessment of the guidelines using the Korean version of the Appraisal of Guidelines for Research and Evaluation II (AGREE II) instrument (\%)

\begin{tabular}{ccccccc}
\hline Domain & $\begin{array}{c}\text { Domain 1. } \\
\text { Scope and } \\
\text { purpose }\end{array}$ & $\begin{array}{c}\text { Domain 2. } \\
\text { Stakeholder } \\
\text { involvement }\end{array}$ & $\begin{array}{c}\text { Domain 3. } \\
\text { Rigor of } \\
\text { development }\end{array}$ & $\begin{array}{c}\text { Domain 4. } \\
\text { Clarity of } \\
\text { presentation }\end{array}$ & $\begin{array}{c}\text { Domain 5. } \\
\text { Applicability }\end{array}$ & $\begin{array}{c}\text { Domain 6. } \\
\text { Editorial } \\
\text { independence }\end{array}$ \\
\hline Guideline 1 & 94 & 72 & 54 & 89 & 0 & 67 \\
Guideline 2 & 67 & 78 & 56 & 89 & 89 & 33 \\
Guideline 3 & 94 & 78 & 90 & 89 & 67 \\
\hline
\end{tabular}

Table 6. Recommendation matrix of the existing guidelines

\begin{tabular}{|c|c|c|}
\hline Source guidelines & Recommendation & Grade of recommendation \\
\hline $\begin{array}{l}\text { Guideline 1: CBCT } \\
\text { in implant dentistry: a } \\
\text { systematic review focusing } \\
\text { on guidelines, indications, } \\
\text { and radiation dose risks }\end{array}$ & $\begin{array}{l}\text { Practitioners who prescribe or use CBCT units should design specific CBCT } \\
\text { equipment protocols that are task specific and incorporate the imaging goal } \\
\text { for patient's specific presenting circumstances. } \\
\text { The protocol should include considerations of exposure (mA and } \mathrm{kVp} \text { ), } \\
\text { minimum image-quality parameters (e.g., number of basis images, } \\
\text { resolution), and restriction of the FOV to visualize adequately the region of } \\
\text { interest. }\end{array}$ & Not available \\
\hline $\begin{array}{l}\text { Guideline } 2 \text { : Consensus } \\
\text { statements and } \\
\text { recommended clinical } \\
\text { procedures regarding } \\
\text { contemporary surgical and } \\
\text { radiographic techniques in } \\
\text { implant dentistry }\end{array}$ & $\begin{array}{l}\text { The clinician performing or interpreting CBCT scans for implant dentistry } \\
\text { should take into consideration current radiologic guidelines. } \\
\text { The decision to perform CBCT imaging for treatment planning in implant } \\
\text { dentistry should be based on individual patient needs following thorough } \\
\text { clinical examination. } \\
\text { - When cross-sectional imaging is indicated, CBCT is preferable over CT. } \\
\text { CBCT imaging is indicated when information supplemental to the clinical } \\
\text { examination and conventional radiographic imaging is considered necessary. } \\
\text { CBCT may be an appropriate primary imaging modality in specific } \\
\text { circumstances (e.g., when multiple treatment needs are anticipated or when } \\
\text { jawbone or sinus pathology is suspected). } \\
\text { - The use of a radiographic template in CBCT imaging is advisable to } \\
\text { maximize surgical and prosthetic information. } \\
\text { - The FOV of the CBCT examination should be restricted to the ROI } \\
\text { whenever possible. } \\
\text { - Patient- and equipment-specific dose reduction measures should be used at } \\
\text { all times. } \\
\text { - To improve image data transfer, clinicians should request radiographic } \\
\text { devices and third-party dental implant software applications that offer fully } \\
\text { compliant DICOM data export. }\end{array}$ & Not available \\
\hline $\begin{array}{l}\text { Guideline } 3 \text { : Radiation } \\
\text { No. } 172 \text { CBCT for } \\
\text { dental and maxillofacial } \\
\text { radiology (evidence-based } \\
\text { guidelines) }\end{array}$ & $\begin{array}{l}\text { CBCT is indicated for cross-sectional imaging prior to implant placement as } \\
\text { an alternative to existing cross-sectional techniques where the radiation dose } \\
\text { of CBCT is shown to be lower. } \\
\text { D } \\
\text { For cross-sectional imaging prior to implant placement, the advantage of } \\
\text { CBCT with adjustable fields of view, compared with MSCT, becomes greater } \\
\text { where the region of interest is a localized part of the jaws, as a similar-sized } \\
\text { field of view can be used } \\
\text { GP }\end{array}$ & $\mathrm{D}, \mathrm{GP}$ \\
\hline
\end{tabular}

CBCT: cone-beam computed tomography, FOV: field of view, ROI: region of interest, DICOM: Digital Imaging and Communications in Medicine, MSCT: multislice computed tomograph

Guideline 1: CBCT in implant dentistry: a systematic review focusing on guidelines, indications, and radiation dose risks ${ }^{6}$
Guideline 2: Consensus statements and recommended clinical procedures regarding contemporary surgical and radiographic techniques in implant dentistry ${ }^{7}$ 
Table 7. Results of the assessment of acceptability and applicability

\begin{tabular}{|c|c|c|c|c|}
\hline & $\begin{array}{c}\text { Acceptability } \\
\text { and applicability }\end{array}$ & $\begin{array}{l}\text { Guideline } 1 . \\
\text { Bornstein et al. }\end{array}$ & $\begin{array}{c}\text { Guideline } 2 . \\
\text { Bornstein et al. }^{7}\end{array}$ & $\begin{array}{l}\text { Guideline } 3 . \\
\text { European commission }\end{array}$ \\
\hline \multirow[t]{4}{*}{ Acceptability } & Similarity of population & Yes & Yes & Yes \\
\hline & Similarity of value and preference & Yes & Yes & Yes \\
\hline & Similarity of benefit by recommendation & Yes & Yes & Yes \\
\hline & Generally, acceptable & Yes & Yes & Yes \\
\hline \multirow[t]{4}{*}{ Applicability } & Applicability of intervention/instrument & Yes & Yes & Yes \\
\hline & Applicability of essential technique & Yes & Yes & Yes \\
\hline & No legal and institutional barriers & Yes & Yes & Yes \\
\hline & Generally, applicable & Yes & Yes & Yes \\
\hline
\end{tabular}

Guideline 3: Radiation No. 172 CBCT for dental and maxillofacial radiology (evidence-based guidelines) ${ }^{8}$

Conventional imaging was recommended in all 3 guidelines as an appropriate examination modality for patients scheduled for implant placement. If insufficient information is obtained via conventional imaging, CBCT can be a next step. The domestic acceptability and applicability of the 3 guidelines were acceptable (Table 7).

\section{Grading the level of evidence and drafting the recommendation document}

Based on the 3 guidelines (Table 6), 3 recommendations were proposed, for which the recommendation grade and evidence level are as follows:

Recommendation 1. In the absence of a clinical abnormality in the oral cavity, a panoramic X-ray examination and periapical radiological examination of the relevant part of the alveolar bone are necessary to determine the status of the bone and the shape of adjacent anatomical structures (recommendation grade A, evidence level II).

Recommendation 2. A CBCT scan should be performed for each patient judged to require a cross-sectional image after reading of the panoramic X-ray image and intraoral radiological image (recommendation grade $\mathrm{B}$, evidence level II).

Recommendation 3. A CBCT scan can be used as the primary test for patients clinically suspected to have pathological abnormalities of the jaw or the maxillary sinus (recommendation grade B, evidence level II).

\section{Finalizing the recommendation document}

Reviews can be performed using different methods, such as conducting a seminar to hear directly from the users and holding a public meeting with the head of the Consumer Protection Committee, newspaper reporters, and healthcare officials. To make this guideline useful for clinicians who request imaging examinations, the recommendations will be disseminated widely through diverse methods, such as academic presentations and public communication. The developed Korean clinical imaging diagnostic guideline (K-CIG) will be re-assessed annually, and may be revised if new key evidence is presented.

\section{Discussion}

This study aimed to develop a guideline for the appropriate use of various radiographical modalities for Korean patients scheduled for implantation. In the future, we will use this method to create a Korean guideline for more than 50 PICO questions that clinicians would like to be clarified. Joint recommendations were made by the KAOMFR and NECA, following the adaptation process of evidence-based CIGs. One of the 3 selected guidelines was identified through a manual search, because the guideline developed by the SEDENTEXCT research project is only provided on their website. Therefore, the compiled guideline has been posted for easy access worldwide. Furthermore, we will create a mobile application for this guideline, which will make it easy for end-users to see the guideline on their mobile phones.

All 3 guidelines for the method of examination of patients scheduled for implantation, which received scores $>50$ scores in the "rigor of development" domain, uniformly recommended conventional imaging, such as panoramic radiography. It was recommended to use a panoramic radiograph to decide whether a CBCT scan is necessary.

We recommended CBCT scanning in individual patients judged to require a cross-sectional image after reading of a panoramic X-ray image and a conventional intra-oral 
radiological image. ${ }^{6,9}$ More specifically, a cross-sectional image after panoramic radiography is needed in the following conditions in the maxilla: ${ }^{8}$ (a) an incisive canal, (b) descent of the maxillary sinus, (c) doubt regarding the sinus septum in sinus grafting, (d) doubt about the shape of the alveolar ridge, and (e) pathosis. In the mandible, the conditions requiring a cross-sectional image are: (a) doubt about the position of the mandibular canal or mental foramen, (b) doubt about the shape of the alveolar ridge, (c) severe resorption, and (d) pathosis.

A benefit of CBCT is that it provides a cross-sectional view of the residual alveolar bone with a lower radiation dose than multislice computed tomography (MSCT). Additionally, when acquiring images using a radiological marker, an appropriate plan can be made considering the implant direction. However, CBCT is inadequate for evaluating bone quality. Unlike MSCT, the grayscale values in CBCT images are not reliable; thus, evaluating density objectively is challenging. However, the grayscale values of CBCT images have been reported to be correlated with implant retention. ${ }^{10}$ Evaluating the residual alveolar bone using CBCT has the advantages of less radiation exposure than conventional MSCT and an adjustable field of view so that clinicians can observe only the necessary part. ${ }^{8}$

The radiation dose for each examination was $7.2 \mu \mathrm{Sv}$ for panoramic radiography, ${ }^{11} 1-8.3 \mu \mathrm{Sv}$ for periapical radiography, ${ }^{12}$ and 11-674 $\mu \mathrm{Sv}$ for CBCT of the alveolar bone. ${ }^{8}$ Since CBCT has a large effective dose difference depending on the region of interest, it is recommended to adjust the exposed site based on the ROI. ${ }^{13}$

The working group gathered guidelines and determined their domestic acceptability and applicability through consensus.

We have prepared a plan for effective dissemination of this guideline by consensus of the committee to strengthen its application. To improve the applicability of the generated guideline, we will publish articles in leading journals and create and use a clinical decision support system as a domestic mobile application.

In conclusion, this study was the first to develop an evidence-based CIG for implant planning in Korea. As subsequent activities, applicability and monitoring are recommended to ensure that the application of the guideline in clinical settings is fully justified. Additionally, K-CIG should be regularly reviewed and revised.

\section{References}

1. Harris D, Horner K, Gröndahl K, Jacobs R, Helmrot E, Benic GI, et al. E.A.O. guidelines for the use of diagnostic imaging in implant dentistry 2011. A consensus workshop organized by the European Association for Osseointegration at the Medical University of Warsaw. Clin Oral Implants Res 2012; 23: 1243-53.

2. Fienitz T, Schwarz F, Ritter L, Dreiseidler T, Becker J, Rothamel D. Accuracy of cone beam computed tomography in assessing peri-implant bone defect regeneration: a histologically controlled study in dogs. Clin Oral Implants Res 2012; 23: 8827.

3. Bornstein MM, Horner K, Jacobs R. Use of cone beam computed tomography in implant dentistry: current concepts, indications and limitations for clinical practice and research. Periodontol 2000 2017; 73: 51-72.

4. Choi SJ, Jeong WK, Jo AJ, Choi JA, Kim MJ, Lee M, et al. Methodology for developing evidence-based clinical imaging guidelines: joint recommendations by Korean Society of Radiology and National Evidence-Based Healthcare Collaborating Agency. Korean J Radiol 2017; 18: 208-16.

5. Brouwers MC, Kho ME, Browman GP, Burgers JS, Cluzeau F, Feder G, et al. AGREE II: advancing guideline development, reporting and evaluation in health care. CMAJ 2010; 182: E839-42.

6. Bornstein MM, Scarfe WC, Vaughn VM, Jacobs R. Cone beam computed tomography in implant dentistry: a systematic review focusing on guidelines, indications, and radiation dose risks. Int J Oral Maxillofac Implants 2014; 29 Suppl: 55-77.

7. Bornstein MM, Al Nawas B, Kuchler U, Tahmaseb A. Consensus statements and recommended clinical procedures regarding contemporary surgical and radiographic techniques in implant dentistry. Int J Oral Maxillofac Implants 2014; 29 Suppl: 78-82.

8. SEDENTEXCT Guideline Development Panel. Radiation protection No 172. Cone beam CT for dental and maxillofacial radiology. Evidence based guidelines. Luxembourg: European Comminssion Directorate-General for Energy; 2012.

9. Jacobs R, Salmon B, Codari M, Hassan B, Bornstein MM. Cone beam computed tomography in implant dentistry: recommendations for clinical use. BMC Oral Health 2018; 18: 88.

10. Arisan V, Karabuda ZC, Avsever H, Özdemir T. Conventional multi-slice computed tomography $(\mathrm{CT})$ and cone-beam $\mathrm{CT}$ (CBCT) for computer-assisted implant placement. Part I: relationship of radiographic gray density and implant stability. Clin Implant Dent Relat Res 2013; 15: 893-906.

11. Lee C, Lee SS, Kim JE, Symkhampha K, Lee WJ, Huh KH, et al. A dose monitoring system for dental radiography. Imaging Sci Dent 2016; 46: 103-8.

12. Gijbels F, Jacobs R, Sanderink G, De Smet E, Nowak B, Van Dam J, et al. A comparison of the effective dose from scanography with periapical radiography. Dentomaxillofac Radiol 2002; 31: 159-63.

13. Jacobs R, Quirynen M. Dental cone beam computed tomography: justification for use in planning oral implant placement. Periodontol 2000 2014; 66: 203-13. 